Proc. Estonian Acad. Sci. Eng., 2006, 12, 4, 464-475

\title{
Inductive method for the measurement of surface layer characteristics of ferromagnetic materials
}

\author{
Jonas Vilys ${ }^{\mathrm{a}}$, Antanas Ciuplys ${ }^{\mathrm{a}}$, Vytautas Ciuplys ${ }^{\mathrm{a}}$ and Valdas Kvedaras ${ }^{\mathrm{b}}$ \\ a Department of Metals Technology, Kaunas University of Technology, Kestucio St. 27, LT-44025 \\ Kaunas, Lithuania; jonas.vilys@ktu.lt \\ b Department of Technological Processing, Klaipeda University, Bijunu St. 17, LT-91225 Klaipeda, \\ Lithuania; valdas.kvedaras@ku.lt
}

Received 14 June 2006, in revised form 29 September 2006

\begin{abstract}
The main objective of the work is to propose a quick inductive method for the measurement of the characteristics of the modified surface layer of ferromagnetic materials. The investigation of the depth of the strain-hardened layer and the development of micro-non-uniform deformation in a sample after plastic deformation was carried out by this method. Experiments confirm the potential of the inductive method for quick and non-destructive control of surface layer characteristics of ferromagnetic materials. This method allows to conduct a constant monitoring of manufactured production without interrupting the production process. During the production process it gives the possibility to react to the changes more effectively and to reduce down time and costs.
\end{abstract}

Key words: inductive measurement method, non-destructive control, ferromagnetic materials, strain hardened layer, micro-non-uniform deformation.

\section{INTRODUCTION}

Investigation of the influence of the surface layer on the physical-mechanical properties and heterogeneity of plastic deformation of metals sometimes meets difficulties related to the determination of the depth of that layer and local character of stress distribution in it, especially in the range of small strains. It is important to determine quickly the precise depth of the strain-hardened nearsurface layer during the manufacturing process. Radiography, microhardness measurements, measurement of the residual stress distribution, decoding of dislocations, metallographic methods, method of different etching rate of the 
stressed and not stressed areas of the crystal and other methods are used at present for the determination of this characteristic $\left[{ }^{1,2}\right]$. However, all these methods are time and labour consuming and not sufficiently precise.

Magnetic Barkhausen noise method and eddy current method are more precise and non-destructive. Magnetic Barkhausen noise (MBN) is a phenomenon that occurs when a ferromagnetic material is subjected to an alternating external magnetic field, which induces discontinuous changes in its magnetization $\left[{ }^{3-5}\right]$. All ferromagnetic materials have a domain structure with different magnetization regions, polarized in one direction and separated by Bloch walls $\left[^{6}\right]$. When magnetic field is applied to ferromagnetic materials, the increase in flux density takes place in a discontinuous manner as a result of rotation of magnetic domain walls and breaking away from their original positions. These sudden changes in the magnetization result in micro eddy currents, which can be picked up by a coil as a noise signal near the surface of the material.

The MBN is sensitive to many properties of the material such as grain size, composition of the material, hardness, residual stress and fatigue $\left[{ }^{7,8}\right]$. Due to this, the MBN can be used as a potential tool for non-destructive measurement of metallurgical, microstructural and mechanical parameters.

This method is based on the analysis of the power spectrum of the MBN. Usually sensors of the MBN react to a pickup coil, which is placed on the surface of the tested material. Some transducers of the MBN have an auxiliary coil for measuring the magnetizing flux $\left[{ }^{9}\right]$.

Complex resistance of an eddy current transducer depends on many characteristics of the tested object (electrical conductivity, magnetic permeability, thickness and temperature), i.e. the information provided by a transducer about an object is multifunctional $\left[{ }^{10}\right]$. It may have both benefits and drawbacks. On the one hand, the eddy current method permits to perform control of several parameters simultaneously; on the other hand, this method requires special measures to distinguish the information regarding different parameters of the object. When one of the parameters is being measured, the influence of other parameters is undesirable.

The eddy currents, which are used in the research on ferromagnetic materials and cause heat losses, determine the increase of coil resistance and the reduction of inductance. A small surface defect and a big defect in deeper layers can equally influence the amplitude of the signal in a measurement coil. However, these defects can be identified providing a graphical view of the apparent resistance of the measurement coil.

Trying to investigate the characteristics of a surface layer of the material, it is possible to carry out measurements by exciting a converter of eddy currents with various frequencies, thus accumulating information from different layers of the material. Such a measurement technique by exciting a converter of eddy currents with various frequencies is not operative and not accurate, because the properties of upper layers prevail $\left[{ }^{11}\right]$. Using the MBN and eddy current methods, it is hard to perform measurements in the desirable place, i.e. in a small area (for example, 
in a grain of $30 \mu \mathrm{m}$ ) and complicated equipment is required for the measurements.

Taking the above into consideration, the problem of developing a simple, reliable and rapid method for determining the depth of the strain-hardened surface layer and local character of stress distribution in this layer without damaging a surface, remains.

The main objective of the work is to propose a quick method for the measurement of the characteristics of the modified surface layer of ferromagnetic materials and to analyse them. Plastically deformed metal in the prestrained layer, differently from the strained main metal, is characterized by high concentration of microdefects such as motionless dislocations, vacancies of atoms of interference and their interaction, which restrict their mobility, and results in metal strain-hardening during prestrain. The above-mentioned increases magnetic viscosity of steel $\left[{ }^{12,13}\right]$. As a result, the coercive force increases and the residual inductance and magnetic penetration decrease $\left[{ }^{14}\right]$. Using the above-described changes of the properties of ferromagnetic materials, influenced by applied mechanical stresses, tests were carried out with the aim to check the possibility to use these properties for local determination of plastic deformations.

The main point of the method is the following. If deformed ferromagnetic material is placed into a magnetic field, the magnetic inductance will change depending on the change of magnetic penetration. The same happens when ferromagnetic part touches the core of the magnetic coil. Measuring the change of the coil inductance, it is possible to measure stress changes in the ferromagnetic body.

A schematic diagram of the inductive device is shown in Fig. 1. The action of the device is based on the principle of the resonant method of measurements with

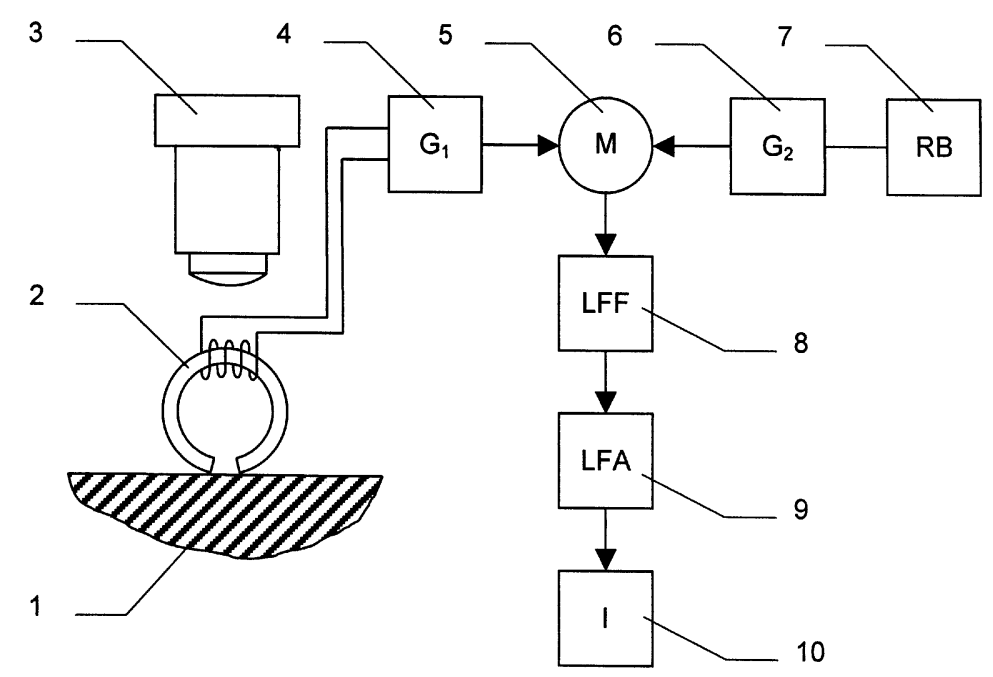

Fig. 1. A schematic diagram of inductive measurement: 1-sample, 2-magnetic probe, 3 - objective, 4 - first high-frequency generator, 5 - mixer, 6 - second high-frequency generator, 7 - regulation block, 8 - low-frequency filter, 9 - low-frequency amplifier, 10 - indicator. 
an inductance at the moment of a resonance on zero beating. Two generators of high frequency, $G_{1}$ and $G_{2}$, are assembled in the inductive device according to the same electric scheme. The magnetic probe is attached to the first generator $G_{1}$. Frequency of the second generator $\mathrm{G}_{2}$ is changed by regulation block RB. Oscillation of high frequency from both generators goes to mixer, then through low frequency filter LFF and low frequency amplifier LFA to indicator I. When magnetic probe is attached to the generator $G_{1}$, the frequency of the second generator $\mathrm{G}_{2}$ is changed by the regulation block till the indicator shows the fluctuation of zero. The inductance is determined by indications of the regulation block.

The magnetic probe, which was fastened directly to an objective of a microscope by the holder, was made of the magnetic head of the tape recorder. The working gap of the magnetic probe can be adjusted depending on the measurement base. Position of the working gap of the magnetic probe was established by the screws in such a way that sharp ends of the probe were in the focus of the microscope.

During measurements, the electromagnetic probe with the micrometric screw of the microscope is brought to the sample surface, up to the contact with it. Then inductance of the probe is measured. Since the gap of the probe is shunted by the part of the sample between the ends of the probe, its inductance depends on the magnetic penetration of the given sample area and on the mechanical stress in the probe covered site of the near-surface layer of the sample.

Anisotropy of physicomechanical properties is to a greater or smaller extent typical to all crystal bodies. Interest in anisotropic properties of crystal bodies has increased considerably in recent years. There is a close relationship between anisotropic properties, development of micro-non-uniform deformation of the polycrystalline conglomerate and strength properties of real polycrystalline alloys. Special attention should be paid to studying laws of micro-non-uniform deformations at the earliest stage of the development of the plastic deformation (the stage of micro-yield) $\left[{ }^{15}\right]$.

In case of polycrystalline metallic materials and alloys with body-centred cubic (BCC) lattice, the periodical and gradual character of plastic deformation processes at monotonic tension can be presented as follows (Fig. 2) $\left[{ }^{16}\right]$. At present, by investigating fracture processes of metallic materials it is accepted to divide all process of strain accumulation and fracture into two basic periods: the period of initiation of cracks and the period of propagation of cracks (the shaded area in Fig. 2). Further we shall consider which basic stages of damage accumulation are relevant to the period of the initiation of cracks at static loading.

The first stage is the stage of micro-yield. This stage lasts from the beginning of the loading until the occurrence of the first lines of sliding on the yield plateau. At this stage, such characteristics as the limit of proportionality and the limit of elasticity are determined. In spite of the fact that residual macrostrains at this stage practically equal to zero, the micro-plastic deformation takes place. For metallic materials with a physical yield limit the end of this stage is precisely fixed by the beginning of non-homogeneous deformation of Lüders $\left[{ }^{17}\right]$. 


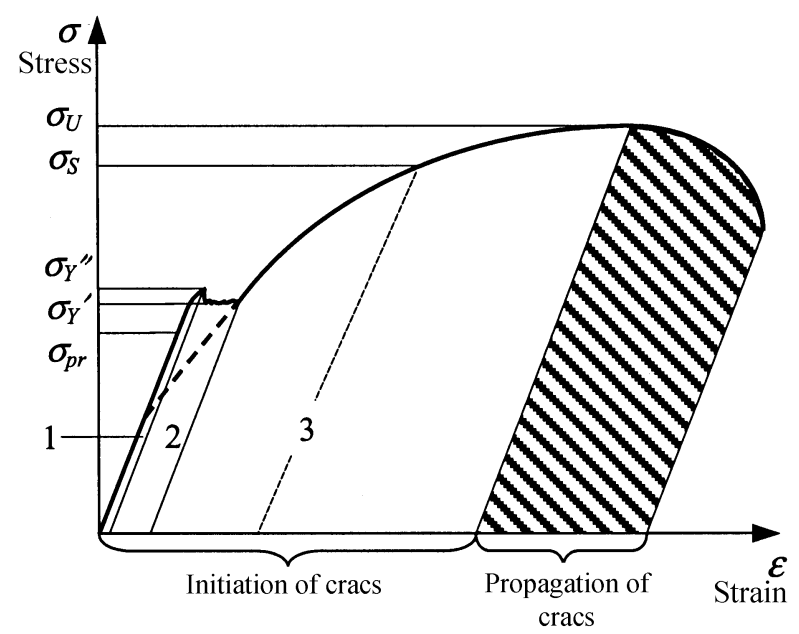

Fig. 2. Failure process stages at static tension of BCC lattice possessing metals.

The second stage is the stage of yield, characterized by non-homogeneous deformation in the form of Lüders front passing along all working length of the sample. In the metals with yield plateau at monotonic tension, heterogeneous deformation on the yield plateau is related to the fast multiplication of dislocations.

The third stage is the stage of strain-hardening. At this stage, in plastic metals and alloys intensive increase of dislocation density is observed. At a certain critical stress $\sigma_{S}$, submicrocracks with the size of approximately 1-3 $\mu \mathrm{m}$ appear on the surface layer of the metal. Inside metal the defective structure is also formed in the areas with critical density of dislocations. This stage finishes at the moment, when maximal load is achieved and the neck formation begins.

The above described periodicity and gradual character of fracture at monotonic tension are characteristic for plastic metallic materials. Obviously, depending on structural conditions of materials and loading conditions (high and low temperatures, strain rate, the environment), character of the fracture may change; however, general laws of gradual damage accumulation are preserved.

However, there is no full and clear understanding of the character of plastic deformation process in microareas of a polycrystalline alloy; in particular, it concerns the distribution of deformations in the stage of microyield. There is a disputable question regarding the beginning of plastic deformation by monotonic tension. Hence, regularities of the distribution of non-uniform deformation in microvolumes of the polycrystalline alloy have not been investigated thoroughly. Such investigations are very valuable because the study of micro-non-uniform plastic deformation will help to understand the complex picture of strength and plastic properties of the material as a whole $\left[{ }^{18-22}\right]$.

The inductive method can be used for the above investigations. 


\section{EXPERIMENTAL}

Investigating the depth of the strain-hardened layer and the development of micro-non-uniform deformation of a sample was carried out by the inductive method. Tests were carried out on flat samples of low-carbon steel with the dimensions of a deformable part $3.0 \times 12.0 \times 62.0 \mathrm{~mm}$ (for investigating the depth) and $1.8 \times 12.0 \times 62.0 \mathrm{~mm}$ (for investigating the micro-non-uniform deformation). The chemical composition of this steel is specified in Table 1. Mechanical properties of the steel, subjected to recrystallizing annealing in vacuum of $2 \times 10^{-4} \mathrm{~mm} \mathrm{Hg}$ at $670^{\circ} \mathrm{C}$ for $2 \mathrm{~h}$ are given in Table 2 .

The average size of grains after heat treatment was $30 \mu \mathrm{m}$. Strain rate at monotonic tension was $3.4 \times 10^{-4} \mathrm{~s}^{-1}$.

Samples were strain-hardened with two rolls to different depths. The inductance of the near-surface layer was measured after strain-hardening. The thickness of the near-surface layer of the sample was removed by electrolytic etching. From 10 to 20 stages were required to etch the samples to the desirable depth, i.e. up to the full removal of the strain-hardened metal. The inductance was measured in intervals. The working gap of the magnetic probe was $120 \mu \mathrm{m}$. For more exact fixation of the moment of the full removal of the deformed layer (at the final stage of the experiment), thickness of the removed layer (between separate measurements) was gradually decreased down to $5 \mu \mathrm{m}$.

The thickness of the removed layer in the process of electrolytic etching was calculated using the curve, which describes the relationship between the time of etching and thickness of a removed layer at constant density of electric current, temperature of etching and electrolyte composition. Then the total thickness of all removed layers was determined by the method of weighing according the relationship

$$
\sum_{0}^{N} \Delta \delta_{N}=\frac{\Delta P}{a b \rho}
$$

where $\Delta \delta_{N}$ is thickness of $N$ th layer, etched from the surface, $\Delta P$ is loss of weight of the sample as a result of etching, $a$ and $b$ are the length and width of the sample, respectively, and $\rho$ is density of the material.

Table 1. Chemical composition of low-carbon steel specimens

\begin{tabular}{c|c|c|c|c|c|c}
\hline $\mathrm{C}$ & $\mathrm{Si}$ & $\mathrm{Mn}$ & $\mathrm{Cr}$ & $\mathrm{P}$ & $\mathrm{S}$ & $\mathrm{Ni}$ \\
\hline 0.07 & 0.025 & 0.35 & 0.10 & 0.03 & 0.025 & 0.20
\end{tabular}

Table 2. Mechanical properties of tested low-carbon steel specimens

\begin{tabular}{c|c|c|c}
\hline $\begin{array}{c}\text { Tensile strength } \\
R_{m}, \mathrm{MPa}\end{array}$ & $\begin{array}{c}\text { Yield strength } \\
R_{e}, \mathrm{MPa}\end{array}$ & Elongation $A, \%$ & Contraction $Z, \%$ \\
\hline 360 & 270 & 35 & 60
\end{tabular}


Weight of the etched material was determined with the accuracy of $0.001 \mathrm{~g}$. The thickness of the removed layers was additionally measured with the micrometer.

From the received data, the dependence of the probe inductance on the depth of the removed layer was determined. Figure 3 shows the dependence of the inductance $(L)$ of the probe on the depth of the removed layer $(h)$ in the nearsurface layer of samples from low-carbon steel with different depths of the strain hardened layer. The dotted curve shows the change of inductance in the annealed sample without surface strain hardening. When the curve of inductance of the strain hardened sample coincides with the dotted curve, the thickness of the removed layer corresponds to the depth of the strain-hardened layer.

The inductance can be measured at the surface of the sample without disturbing it and on the basis of that the depth of the strain-hardened layer can be determined.

The inductive method was also used for the investigation of the development of the micro-non-uniform deformation in all stages of deformation. The initial stage of plastic deformation was investigated most carefully. The local character of plastic deformation at a stage of micro-yield in the superficial area of the sample was studied as follows. Using microhardness device PMT-3, marks were made every $200 \mu \mathrm{m}$ along the length of the polished surface of the sample. Aiming to estimate the dependence of anisotropy of material properties in microvolumes of a sample on magnetic penetration, at the beginning inductance measurements were carried out on the marked places of the annealed unloaded sample. The working gap of the magnetic probe was $30 \mu \mathrm{m}$. Further the sample was subjected to certain loading and the inductance of the sample was repeatedly

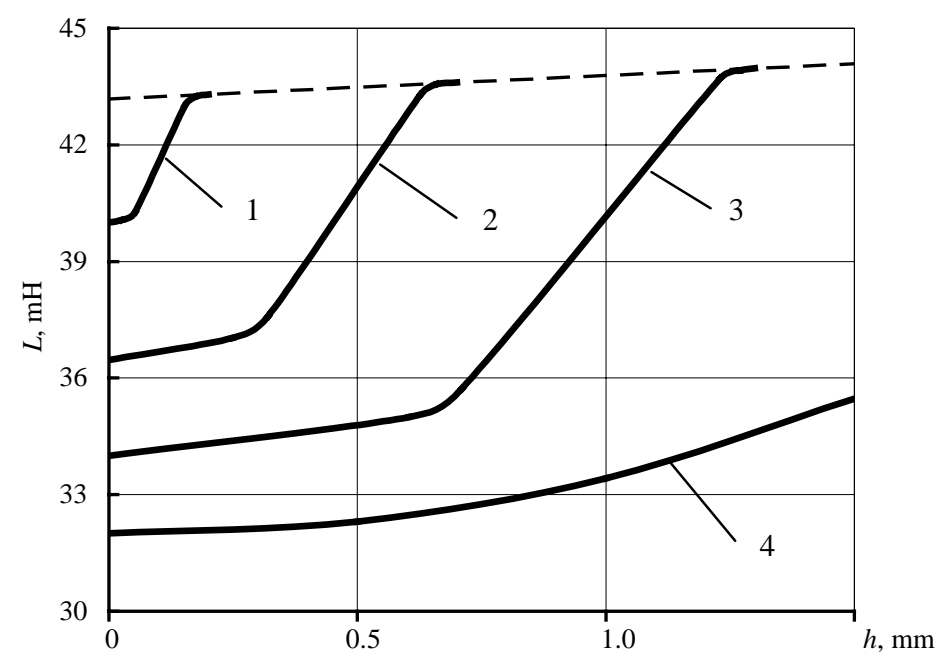

Fig. 3. Dependence of the inductance $(L)$ of the probe on the depth of the removed layer $(h)$ for various depths of the strain-hardened layer: 1 - the depth of the strain hardened layer $0.2 \mathrm{~mm}$, $2-0.7 \mathrm{~mm}, 3-1.3 \mathrm{~mm}, 4-$ strain-hardened in all the cross-section. 
measured, shunting its working backlash by the marked places of the sample, loaded by tensile stress.

From the obtained data the curves of inductance of the probe versus applied load were constructed (Fig. 4). In the figure the length of the deformable part of the sample is $5 \mathrm{~mm}$.

Curve 1 corresponds to the change of inductance of the annealed sample. Curve 2 presents variation of the inductance after the removal of the stress of $80 \mathrm{MPa}$. It is obvious that in the basic part of the sample, after unloading the inductance has increased in comparison with the initial condition. However, in two areas of the sample the inductance has decreased that is shown by the presence of residual stress. Hence, in these zones the limit of elasticity is surpassed. So, after unloading of the sample from the stress not exceeding the limit of elasticity, continuous growth of inductance is observed. The decrease of inductance is observed in those microareas, where local pressure exceeds the limit of elasticity.

The increase of the tensile loading results in further reduction of inductance in earlier deformed areas, which means that the residual stress (curve 3) grows. Reduction of inductance is observed in other areas as well, i.e. plastic deformation occurs also there. However, in some areas of the sample inductance is still increasing, i.e. the limit of elasticity is here not surpassed yet. The moment of the achievement of the yield limit is preceded by the maximum increase of inductance in some areas of the sample.

After unloading of the sample from the stress close to the upper yield limit, in all superficial areas of the sample a noticeable recession of inductance (curve 4) is observed. However, this curve also shows that when the upper yield limit is achieved, a rather big inductance is still observed in one superficial area. It

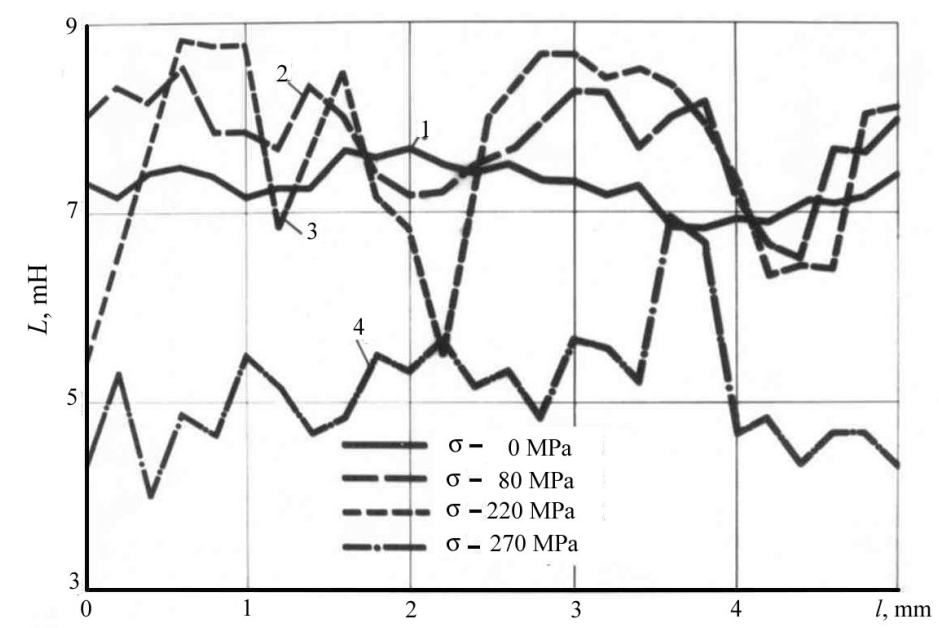

Fig. 4. Dependence of the inductance $(L)$ of the probe on the gage length $(l)$ of a sample of lowcarbon steel depending on the magnitude of the applied stress. 
means that in this area residual stresses have not been formed yet. It is necessary to note that at the end of the first stage of deformation such areas were observed rather seldom.

The tensile loading of a sample at stresses higher than the yield limit (in all stages of yield) has resulted in sharp reduction of the inductance along all length of the deformable part of the sample. Thus, on the basis of inductance change after load removal it is possible to find local volumes of metal, in which the limit of elasticity is surpassed (the inductance in local volumes of metal is reduced), and to determine the moment when the yield limit is achieved (reduction of the inductance in all microvolumes of the sample).

The residual stresses, discovered by the inductive method, show that at the earliest stages of the monotonic tension of a sample attributes of plastic deformation are observed in the elastic region in separate grains of the near-surface layer of the metal. The plastic deformation does not occupy simultaneously all the superficial volume of the metal when the stress increases. The consecutive deformation of separate macrovolumes of the near-surface layer is observed until all macrovolumes are covered by plastic deformation of critical volume. The most intensive spread of plastic deformation to the majority of near-surface grains begins when the elastic limit $\sigma_{e}$ is achieved. Thus, local character of plastic deformation in separate grains is especially strong at small deformations. Hence, local plastic deformation distribution is not steady and it depends on the strain value. The locality decreases during the process of the increase of the plastic deformation. Thus, in a real polycrystalline material under linear tension, as a result of the interaction of differently oriented grains, each grain is in condition of a complex state of stresses and this state is different in every grain.

Local character of plastic deformation distribution in the near-surface layer in the micro-yield stage is observed not only among separate grains, but also in the volume of a single grain. The distribution of deformations in separate zones of a grain was investigated using the inductive method. The working gap of the magnetic probe was $10 \mu \mathrm{m}$. Tests have shown that local plastic deformation basically concentrates on near-boundary sites of grains. The beginning of local plastic deformation at grain boundaries of the near-surface layer is revealed after unloading the sample subjected to $30 \mathrm{MPa}$ stress (that stress makes $11 \%$ of the yield strength).

Analysis of the presented data shows that by deformation of a polycrystalline material the grain boundaries and neighbouring areas, where localization of plastic deformation is possible, play an important role and this should have a significant effect on the strength and plasticity of the material. From the considered data the conclusion may be drawn that in the micro-yield stage local plastic deformation appear and this points out the inevitability of non-elastic processes in metals subject to loading. The first steps of plastic deformation are initiated in the surroundings of elastic non-uniform deformations of the near-surface layer of a material at grain boundaries. By monotonic tension of the low-carbon steel in all other stages of deformation (yield and strain-hardening) the inductive method also shows micro-non-uniform plastic deformation. 
On the basis of our tests it may be concluded that when a polycrystalline sample is subject to tension, the non-uniform field of elastic microstresses occurs inevitably due to elastic anisotropy on grain boundaries of metals. The beginning of plastic deformation in separate microareas of a polycrystal is determined not only by the magnitude of elastic microstresses, but also by strength properties of the given microvolume, depending on its crystallographic orientation. It will predetermine a non-simultaneous start of plastic deformation not only inside of the grains, but also in their separate areas. These phenomena may be explained by the law of minimum energy on deformation of polycrystalline parts. Tests have shown that the places of local bursts of deformation mostly are volumes near grain boundaries in the near-surface layer of the material.

Taking into account the results of our investigation, the inductive method may be recommended for the determination of the depth of the surface strainhardened layer, hardened near-surface layer, layer created by thermochemical treatment, various coatings, etc. The inductive method may by used for the evaluation of the locality of residual stresses and small plastic strains in macroand microvolumes, for the evaluation of change of electromagnetic parameters of metal in the cross-section, for the determination of true elastic limit, degree of strain-hardening, revelation of changes taking place during artificial and natural ageing, initiation and propagation of microcracks, etc., in materials, possessing ferromagnetic features. This method permits to conduct constant monitoring of manufactured production without interrupting of the production process.

\section{CONCLUSIONS}

1. A new inductive quick measurement method for the testing of characteristics of the modified surface layer of ferromagnetic materials is proposed.

2. The depth of the strain-hardened surface layer of low-carbon steel specimens was measured by the inductive method.

3. The development of micro-non-uniform deformation of low-carbon steel specimens at static tension in all stages of deformation was investigated by the inductive method.

4. The inductive method may be recommended for the determination of depth of strain-hardened surface layers as well as for the evaluation of the locality of residual stresses, small plastic strains in macro- and microvolumes and other physical and mechanical characteristics of metals.

5. The experimental investigation confirms the potential of the application of the inductive method for the quick and non-destructive control of surface layer characteristics of ferromagnetic materials. This method permits to conduct constant monitoring of the production without interrupting the production process. 


\section{REFERENCES}

1. Polyak, M. Strengthening Technology, vol. 1. Mashinostrojenie, Moscow, 1995 (in Russian).

2. Polyak, M. Strengthening Technology, vol. 2. Mashinostrojenie, Moscow, 1995 (in Russian).

3. Moorthy, V., Vaidanathan, S., Raj, B., Jayakumar, T. and Kashyap, B. P. Insight into the microstructural characterization of ferritic steels using micromagnetic parameters. Metallurg. Mater. Trans. A, 2000, 31, 1053-1165.

4. Vaidyanathan, S., Moorthy, V., Jayakumar, T. and Raj, B. Evaluation of induction hardened case depth through microstructural characterisation using magnetic Barkhausen emission technique. Mater. Sci. Eng., 2000, 16, 202-208.

5. Spasojevic, D., Bukvic, S., Milosevic, S. and Stanley, H. E. Barkhausen noise: elementary signals, power laws and scaling relations. Phys. Rev. E, 1996, 54, 2531-2546.

6. Kroning, M., Haussler, F. and Arnold, W. Surface analysis by non-destructive testing techniques. Fresenius J. Anal. Chem., 1997, 358, 3-9.

7. Anglada-Rivera, J., Padovese, L. R. and Capo-Sanchez, J. Magnetic Barkhausen noise and hysteresis loop in commercial carbon steel: influence of applied tensile stress and grain size. J. Magn. Magn. Mater., 2001, 231, 299-306.

8. Ng, D. H. L., Cho, K. S., Wong, M. L., Chan, S. L. I., Ma, X.-Y. and Lo, C. C. H. Study of microstructure, mechanical properties, and magnetization process in low carbon steel bars by Barkhausen emission. Mater. Sci. Eng. A, 2003, 358, 186-198.

9. Ramanauskas, R. and Augutis, V. Barkhausen noise transducers. In Proc. Conference on Condition Monitoring. Cambridge, 2005, 393-399.

10. Cartz, L. Nondestructive Testing. Materials Park, Ohio, 1995.

11. Augutis, V., Ramanauskas, R. and Vasauskas, V. Measurement of the mechanical state of subsurface layers by eddy-current method. In Proc. XVII IMEKO World Congress. Dubrovnik, 2003, 1018-1022.

12. O’Sullivan, D., Cotterell, M., Cassidy, S., Tanner, D. A. and Meszaros, I. Magneto-acoustic emission for the characterisation of ferritic stainless steel microstructural state. J. Magn. Magn. Mater., 2004, 271, 381-389.

13. Augutis, V., Ramanauskas, R., Čiuplys, A., Vilys, J. and Čiuplys, V. Determination of metal surface hardened layer depth using magnetic Barkhausen noise. Mater. Sci. (Medziagotyra), 2006, 12, 84-87.

14. Sinha, A. K. Physical Metallurgy Handbook. McGraw-Hill, New York, 2003.

15. Fernandes, J.-V., Menezes, L. F., Rodrigues, D. M., Chaparro, B. M. and Vieira, M. F. Nonuniform deformation after prestrain. Eur. J. Mech. A, Solids, 2000, 19, 209-221.

16. Vilys, J., Čiuplys, V., Čiuplys, A. and Kvedaras, V. Influence of work hardened layer thickness on the mechanical properties of metals. Mater. Sci. (Medziagotyra), 2003, 9, 3-8.

17. Suna, H. B., Yoshidaa, F., Ohmorib, M. and Ma, X. Effect of strain rate on Lüders band propagating velocity and Lüders strain for annealed mild steel under uniaxial tension. Mater. Lett., 2003, 57, 4535-4539.

18. Kramer, J. R., Pangborn, R. and Weissmann, S. Dislocation distribution in plastically deformed metals. In Proc. 27th Sagamore Army Material Research Conference. Lake George, 1980; New York-London, 1983, 103-117.

19. Vilys, J. and Kvedaras, V. Dislocation structure of near surface layers of deformed low-carbon steel. In Proc. 15th International Metallurgical and Material Conference. Hradec nad Moravici, 2006. Ostrava, 2006 (CD-ROM, 8 p.).

20. Čiuplys, A., Vilys, J., Čiuplys, V. and Kvedaras, V. Plastic flow of BCC metals at monotonous static and dynamic cyclic loading. Proc. Estonian Acad. Sci. Eng., 2003, 9, 252-260.

21. Wu, C. H., Hsu, J. and Chen, C. H. Effect of surface stress on the stability of surfaces of stressed solids. Acta Mater., 1998, 46, 3755-3760.

22. Kolmakov, A. G. and Vstovsky, G. V. Multifractal analysis of metallic surface structure changes during mechanical treatment. Mater. Sci. Technol., 1999, 15, 705-710. 


\section{Ferromagneetiliste materjalide pinnakarakteristikute mõõtmise induktiivne meetod}

Jonas Vilys, Antanas Ciuplys, Vytautas Ciuplys ja Valdas Kvedaras

On välja töötatud kiiretoimeline mittepurustav induktiivne meetod ferromagneetiliste materjalide pinnakihi karakteristikute mõõtmiseks. Sellel meetodil on uuritud kalestunud pinnakihi sügavust ja ebaühtlase deformatsiooni levikut plastselt deformeeritud materjalis. 